\title{
Evaluation of toxoplasmosis in pregnant women using dot-immunogold-silver staining with recombinant Toxoplasma gondii peroxiredoxin protein
}

Zhuan-zhuan Liu, Xue-yan Li, Lin-lin Fu, Fei Yuan, Ren-xian Tang, Yi-sheng Liu and Kui-yang Zheng*

\begin{abstract}
Background: Toxoplasma gondii infection endangers human health and affects animal husbandry. Serological detection is the main method used for epidemiological investigations and diagnosis of toxoplasmosis. The key to effective diagnosis of toxoplasmosis is the use of a standardized antigen and a specific and sensitive detection method. Peroxiredoxin is an antigenic protein and vaccine candidate antigen of $T$. gondii that has not yet been exploited for diagnostic application.
\end{abstract}

Methods: In this study, recombinant T. gondii peroxiredoxin protein ( $r \operatorname{TgPrx})$ was prepared and used in dotimmunogold-silver staining (Dot-IGSS) to detect lgG antibodies in serum from mice and pregnant women. The rTgPrx-Dot-IGSS method was established and optimized using mouse serum. Furthermore, serum samples from pregnant women were analyzed by rTgPrx-Dot-IGSS.

Results: Forty serum samples from mice infected with $T$. gondii and twenty negative serum samples were analyzed. The sensitivity and specificity of rTgPrx-Dot-IGSS were 97.5 and 100\%, respectively, equivalent to those of a commercial ELISA kit for anti-Toxoplasma lgG antibody. Furthermore, 540 serum samples from pregnant women were screened with a commercial ELISA kit. Eighty-three positive and 60 negative serum samples were analyzed by rTgPrx-Dot-IGSS. The positive rate was $95.18 \%$, comparable to that obtained with the commercial ELISA kit.

Conclusions: The Dot-IGSS method with rTgPrx as an antigen might be useful for diagnosing T. gondii infection in individuals.

Keywords: Toxoplasma gondii, Peroxiredoxin, Dot-IGSS, Serum, Pregnant women

\section{Background}

Toxoplasma gondii, the causative agent of zoonotic toxoplasmosis, threatens the health of $30 \% \sim 50 \%$ of the population worldwide [1]. Most infections are asymptomatic, but toxoplasmosis can cause abortion, stillbirth, and severe congenital toxoplasmosis in pregnant women

\footnotetext{
* Correspondence: zky@xzhmu.edu.cn

Jiangsu Key Laboratory of Immunity and Metabolism, Department of Pathogen Biology and Immunology, Xuzhou Medical University, Xuzhou 221004, China
}

and life-threatening Toxoplasma encephalitis in immunocompromised patients, such as those with HIV and those who have undergone organ transplantation [2]. Between January 1988 and December 2018, the global prevalence of acute toxoplasmosis in pregnant women was 1.1\%; the highest prevalence was in the Eastern Mediterranean region, and the lowest was in Europe [3]. An estimated 190,100 cases of congenital toxoplasmosis are diagnosed annually worldwide $[4,5]$. In China, the seroprevalence of $T$. gondii in pregnant women

(c) The Author(s). 2020 Open Access This article is licensed under a Creative Commons Attribution 4.0 International License, which permits use, sharing, adaptation, distribution and reproduction in any medium or format, as long as you give appropriate credit to the original author(s) and the source, provide a link to the Creative Commons licence, and indicate if changes were made. The images or other third party material in this article are included in the article's Creative Commons licence, unless indicated otherwise in a credit line to the material. If material is not included in the article's Creative Commons licence and your intended use is not permitted by statutory regulation or exceeds the permitted use, you will need to obtain permission directly from the copyright holder. To view a copy of this licence, visit http://creativecommons.org/licenses/by/4.0/. The Creative Commons Public Domain Dedication waiver (http://creativecommons.org/publicdomain/zero/1.0/) applies to the data made available in this article, unless otherwise stated in a credit line to the data. 
ranges from 2.4 to $5.0 \%$ and is as high as $16.29 \%$ in pregnant Manchu women [6, 7]. Because the optimal treatment strategy for toxoplasmosis is unclear, early diagnosis and intervention are very important so that it can be prevented [8].

Many stages of $T$. gondii can exist in different anatomical locations; thus, diagnosis by etiological methods is difficult. Serological testing is the most commonly used method for clinical diagnosis of T. gondii infection [9]. Enzyme-linked immunosorbent assay (ELISA) is often applied to detect antibodies (IgG, IgM, IgA and IgE) in serum $[9,10]$. This simple method can be used to test many samples simultaneously [11]. However, the quality of commercially available $T$. gondii detection kits is inconsistent, and information on specificity and sensitivity is often lacking [6]. Sensitive, specific and rapid immunological detection methods for toxoplasmosis have long been explored and are greatly needed.

The dot-immunogold-silver staining (Dot-IGSS) method uses the specificity of antigen-antibody binding and the sensitivity of gold-silver particles to detect serum antibodies in patients with parasitic diseases [12, 13]. The sensitivity of Dot-IGSS are higher than those of ELISA for diagnosing schistosomiasis, clonorchiasis, toxoplasmosis and cysticercosis [13-16]. The Dot-IGSS procedure is simple and convenient and, unlike ELISA, does not require a microplate reader. Therefore, DotIGSS can be carried out in township hospitals and community health service centers.

Antigen is a key element in diagnostic methods. Soluble tachyzoite antigen (STAg) and excretory secretion antigen (ESA) of T. gondii are common diagnostic antigens, but these antigens exhibit specificity for certain species and $T$. gondii strains and are thus difficult to standardize $[9,11]$. $T$. gondii peroxiredoxin protein $(\mathrm{TgPrx})$ is an antigenic protein in STAg that has been demonstrated to be detectable by 2-dimensional electrophoresis (2-DE), mass spectrometry (MS) and Western blotting with rabbit anti- $T$. gondii serum [17]. Recombinant TgPrx (rTgPrx) can induce humoral and cellular immune responses that protect mice against lethal T. gondii infection [18]. rTgPrx is thus a novel vaccine antigen for toxoplasmosis, but little is known about its diagnostic applications.

Here, rTgPrx was prepared, purified and used as a standardized antigen. We then combined the sensitivity of Dot-IGGS with the specificity of rTgPrx to detect antibodies against $T$. gondii in serum, demonstrating a new and convenient diagnostic method for toxoplasmosis.

\section{Methods}

\section{Ethics statement}

The animal model was established according to the Guidelines for the Laboratory Animal Use and Care Committee of the Ministry of Health, China, and the
Ethics Committee on Animal Research of Xuzhou Medical University (No. SCXK < SU > 2014-0003). All serum samples from pregnant women were provided by Xuzhou Maternity and Child Health Care Hospital. Written informed consent was provided by each participant.

\section{Preparation of $r T g P r x$}

The recombinant plasmid pGEX-6P-1/TgPrx was constructed. The positive plasmid was transformed into $E$. coli BL21 and induced by isopropyl- $\beta$-D-thiogalactoside (IPTG) [19]. Soluble rTgPrx was purified via glutathione S-transferase (GST) affinity chromatography and identified by Western blotting. PreScission Protease (GE Healthcare, U.S.A.) was used to cleave the GST tag from the rTgPrx fusion protein. The purity of rTgPrx was calculated using Imag J software [20]. The concentration of rTgPrx was measured using a BCA protein assay kit (Thermo Scientific, U.S.A.).

\section{Parasite and animals}

T. gondii tachyzoites ( $\mathrm{RH}$ strain) were provided by $\mathrm{Pe}$ king University Health Science Center (Beijing, China). Snails confirmed to be infected with Schistosoma japonicum cercariae were purchased from the Jiangsu Institute of Parasitic Diseases. Plasmodium berghei was passaged in the laboratory. Fish confirmed to be infected with Clonorchis sinensis metacercariae were donated by the Department of Parasitology, Sun Yat-Sen University. Six-week-old female BALB/c mice were purchased from Beijing Vital River Laboratory Animal Technology, and feeding in specific pathogens free environment. After collecting blood from the canthus, mice were anesthetized with isoflurane and then sacrificed by cervical dislocation.

\section{Preparation of test serum}

$T$. gondii tachyzoites were cultured in human foreskin fibroblasts (HFFs) [21]. HFFs infected with tachyzoites were collected, centrifuged at $985 \times g$ for $10 \mathrm{~min}$ and washed twice with phosphate-buffered saline (PBS). Each pellet was resuspended in an appropriate amount of PBS, sonicated, and centrifuged at $12000 \times g$ for $15 \mathrm{~min}$ at $4{ }^{\circ} \mathrm{C}$ [22]. The supernatant, which contained STAg from T. gondii, was collected, aliquoted, and stored at $-80^{\circ} \mathrm{C}$. The concentration of STAg was measured using a BCA protein assay kit.

Forty mice were subcutaneously injected with a mixture of STAg ( $20 \mu \mathrm{g}$ per mouse) and an equivalent volume of Freund's complete adjuvant (Sigma, U.S.A.). Two weeks later, a second immunization was performed with an emulsion of STAg in an equal amount of Freund's incomplete adjuvant (Sigma, U.S.A.). One week later, a third immunization was performed with the same dose 
and method as the second immunization. One week after the final immunization, serum was collected and analyzed by ELISA. Negative control serum was prepared from twenty mice immunized with PBS.

Thirty mice randomly divided into 10 mice per group were used to prepare serum samples of $C$. sinensis, $S$. japonicum and $P$. berghei infection. Each mouse was gavaged with 45 metacercariae, and $C$. sinensis-positive serum was collected one month later [23]. S. japonicumpositive serum was prepared by infecting mice (40 cercariae per mouse) percutaneously in a shaved region of the abdomen [24]. Mice were intraperitoneally inoculated with $1 \times 10^{6} \mathrm{P}$. berghei parasites [25]. Tail vein blood smears were prepared and stained with Giemsa. Serum was collected when the percentage of infected red blood cells exceeded $50 \%$. All serum samples were maintained at $-20^{\circ} \mathrm{C}$ for later use.

\section{Detection of serum by dot-IGSS assay}

Preparation of a colloidal gold-labeled secondary antibody Colloidal gold particles $(5 \mathrm{~nm})$ were prepared by the tannic acid-trisodium citrate mixed reduction method [26]. Solution A $(2.5 \mathrm{~mL}$ of $1 \% \mathrm{HAuCl}$ and $197.5 \mathrm{~mL}$ of $\left.\mathrm{ddH}_{2} \mathrm{O}\right)$ and solution $\mathrm{B}(10 \mathrm{~mL}$ of $1 \%$ sodium citrate, $1.75 \mathrm{~mL}$ of $1 \%$ citric acid, $0.5 \mathrm{~mL}$ of $0.1 \mathrm{M} \mathrm{K}_{2} \mathrm{CO}_{3}$, and $37.5 \mathrm{~mL}$ of $\mathrm{ddH}_{2} \mathrm{O}$ ) were prepared separately and preheated to $60^{\circ} \mathrm{C}$ with magnetic stirring. Solution $\mathrm{B}$ was quickly poured into solution $\mathrm{A}$, and the mixture was boiled for $5 \mathrm{~min}$ after it turned dark red. The $\mathrm{pH}$ of the colloidal gold solution was adjusted to 9.0 using $0.1 \mathrm{~mol} /$ $\mathrm{L} \mathrm{K}_{2} \mathrm{CO}_{3}$. Then, $0.2 \mathrm{~mL}$ of goat anti-mouse or goat antihuman IgG $(2 \mathrm{mg} / \mathrm{mL})$ (Zhongshan Gold Bridge, China) was added to $40 \mathrm{~mL}$ of the above solution, and the mixture was stirred continuously for $20 \mathrm{~min}$. Then, $4 \mathrm{~mL}$ of $10 \%$ bovine serum albumin (BSA) was added, and the mixture was stirred for $20 \mathrm{~min}$. The supernatant was collected after centrifugation at $1500 \times g$ for $30 \mathrm{~min}$. The precipitate was collected after centrifugation at $12000 \times g$ for $60 \mathrm{~min}$ and dissolved in $4 \mathrm{~mL}$ of Tris Buffered Saline (TBS) $\left(1.12 \mathrm{~g}\right.$ of Tris, $8.8 \mathrm{~g}$ of $\mathrm{NaCl}$, and $1 \mathrm{~L}$ of $\mathrm{ddH}_{2} \mathrm{O}$, adjust $\mathrm{pH}$ to 7.5 with hydrochloric acid). The colloidal gold- labeled secondary antibody was stored at $-20^{\circ} \mathrm{C}$.

\section{Dot-IGSS assay}

Pieces of nitrocellulose (NC) membrane were placed in separate wells of a 96-well plate [16]. $r \operatorname{TgPrx}(1 \mathrm{mg} / \mathrm{mL}$, $1 \mu \mathrm{L}$ ) was added to the NC membranes, and the membranes were allowed to air dry. At the beginning of the experiment, the type of blocking solution, the blocking time, the dilution ratios of mouse serum and the colloidal gold-labeled secondary antibody were optimized (Additional files 1: Fig. S4, S5). Determined after exploration, the dried $\mathrm{NC}$ membranes were blocked in TBS containing $1 \%$ BSA and $10 \%$ goat serum at $37^{\circ} \mathrm{C}$ for 30 min. Diluted serum (mouse, 1:200; human, 1:100) was added to the sample wells and incubated at $37^{\circ} \mathrm{C}$ for 1.5 $h$. The serum was removed from each well, and the wells were washed three times with TBS for 5 min each. Diluted secondary antibody solution (1:20) was added to each well, and the plate was incubated at $37^{\circ} \mathrm{C}$ for $1.5 \mathrm{~h}$. The secondary antibody solution was removed from each well, and the plate was washed sequentially with TBS, deionized water and distilled water. Silver nitrate solution was added to each well, and the plate was incubated in the dark for $7 \mathrm{~min}$. The reaction was terminated by rinsing with ionized water, and the membranes were air dried. Brownish gray or brownish yellow spots on the $\mathrm{NC}$ membranes indicated positive serum. The negative control serum and blank control were also tested via the above method.

\section{Assessment of the sensitivity, specificity, and reproducibility of the dot-IGSS assay}

Serum samples from mice and humans were simultaneously analyzed by Dot-IGSS with rTgPrx as the antigen (rTgPrx-Dot-IGSS), ELISA using rTgPrx as the antigen (rTgPrx-ELISA), Western blotting and a commercial ELISA kit for sensitivity analysis. Serum samples from mice infected with C. sinensis, S. japonicum and P. berghei were used for specificity analysis. Each serum sample was tested three times for repeatability analysis.

\section{Diagnosis by ELISA with serum.}

Serum samples from mice and humans were analyzed with a commercial ELISA kit for the anti-Toxoplasma IgG antibody (Haitai Biotech, China) following the manufacturer's protocol. In brief, diluted serum (1:100, $100 \mu \mathrm{L}$ per well) was added to the wells and incubated at $37^{\circ} \mathrm{C}$ for $30 \mathrm{~min}$. After washing, an enzyme-labeled antibody ( $50 \mu \mathrm{L}$ per well) was added, and the plate was incubated at $37^{\circ} \mathrm{C}$ for $30 \mathrm{~min}$. The colored substrate solution was added, and the plate was incubated at $37^{\circ} \mathrm{C}$ for 15 min in the dark. The reaction was then stopped, and the absorbance at $450 \mathrm{~nm}$ (A450 nm) was measured with a microplate reader (ASYS-Hitech GmbH, U.S.A.).

Serum samples from mice and humans were analyzed by rTgPrx-ELISA. A 96-well microtiter plate was coated with rTgPrx $(1 \mu \mathrm{g} /$ well $)$ and incubated at $4{ }^{\circ} \mathrm{C}$ for $12 \mathrm{~h}$. After blocking at $37^{\circ} \mathrm{C}$ for $1 \mathrm{~h}$, diluted serum (mouse, 1: 200; human, 1:100) was added to the wells, and the plate was incubated at $37^{\circ} \mathrm{C}$ for $12 \mathrm{~h}$. Unbound serum antibody was then washed away, and the samples were incubated with horseradish peroxidase (HRP)-conjugated goat anti-mouse IgG (diluted 1:5000) or goat antihuman IgG (diluted $1: 2500$ ) at $37^{\circ} \mathrm{C}$ for $2 \mathrm{~h}$. Ophenylenediamine was the substrate solution; after it was added, the plate was protected from light for 15 min. The reaction was stopped, and the absorbance at 
$492 \mathrm{~nm}$ (A492 nm) was measured within $20 \mathrm{~min}$. Each sample was independently analyzed three times, and the average value was calculated [27].

\section{Western blotting}

rTgPrx $(20 \mu \mathrm{g})$ was separated via sodium dodecyl sulfate-polyacrylamide gel electrophoresis (SDS-PAGE) on $12 \%$ gels and transferred to polyvinylidene difluoride membranes. Membranes were incubated with mouse serum or human pregnancy serum (diluted 1:100) at $4{ }^{\circ} \mathrm{C}$ overnight and were then probed with an HRPconjugated goat anti-mouse or anti-human IgG antibody (diluted 1:5000, Zhongshan Gold Bridge, China).

\section{Statistical analysis}

Data were analyzed using SPSS software. The positive rates were compared between groups with corrected chisquare tests or Fisher's exact test. Fisher's exact test was used to compare the positive rate of different batches. A significance level $(\alpha)$ of 0.05 was selected, and $P<0.05$ was considered to indicate statistical significance.

\section{Results}

\section{Identification of the rTgPrx}

Expression of the positive recombinant plasmid pGEX6P-1/TgPrx in E. coli was optimized from IPTG concentration, induced temperature and times (Additional files 1: Fig. S1, S2, S3). Finally, pGEX-6P-1/TgPrx was induced by $0.1 \mathrm{mM}$ IPTG at $25^{\circ} \mathrm{C}$ for $12 \mathrm{~h}$, and the protein was purified by GST affinity chromatography. SDS-
PAGE showed that the molecular weight of GST-tagged rTgPrx was $51 \mathrm{kDa}$ (Fig. 1a). The GST tag was cleaved from rTgPrx with PreScission Protease. The molecular weights of the GST tag and rTgPrx were $26 \mathrm{kDa}$ and 25 $\mathrm{kDa}$, respectively (Fig. 1a). The analysis of Imag J software showed that the purity of rTgPrx protein on SDSPAGE was calculated as $95.6 \%$. The purifiedrTgPrx could be recognized by rabbit anti-T.gondii serum. The result of Western blotting showed the specific strips (Fig. 1b). Those results confirmed the acquisition of purified rTgPrx.

\section{Evaluation of $T$. gondii infection in mice by dot-IGSS Testing of mouse serum samples}

The diagnostic potential of rTgPrx was evaluated by Dot-IGSS. Serum positive for T. gondii was collected from mice immunized with STAg (the titers of immunized mouse serum were 1:800 and 1:1600), while serum negative for $T$. gondii was obtained from mice immunized with PBS. As determined by checkerboard titration, the optimal dilution ratios of the mouse serum and goat anti-mouse gold-labeled antibody for the Dot-IGSS assay were 1:200 and 1:20, respectively (Additional files 1: Fig. S5). In this study, 40 positive and 20 negative serum samples from mice were analyzed by Dot-IGSS using rTgPrx as the antigen (Additional files 1: Fig. S6). Thirty-nine of the 40 serum samples from mice immunized with STAg were positive, while all of the 20 serum samples from mice immunized with PBS were negative.

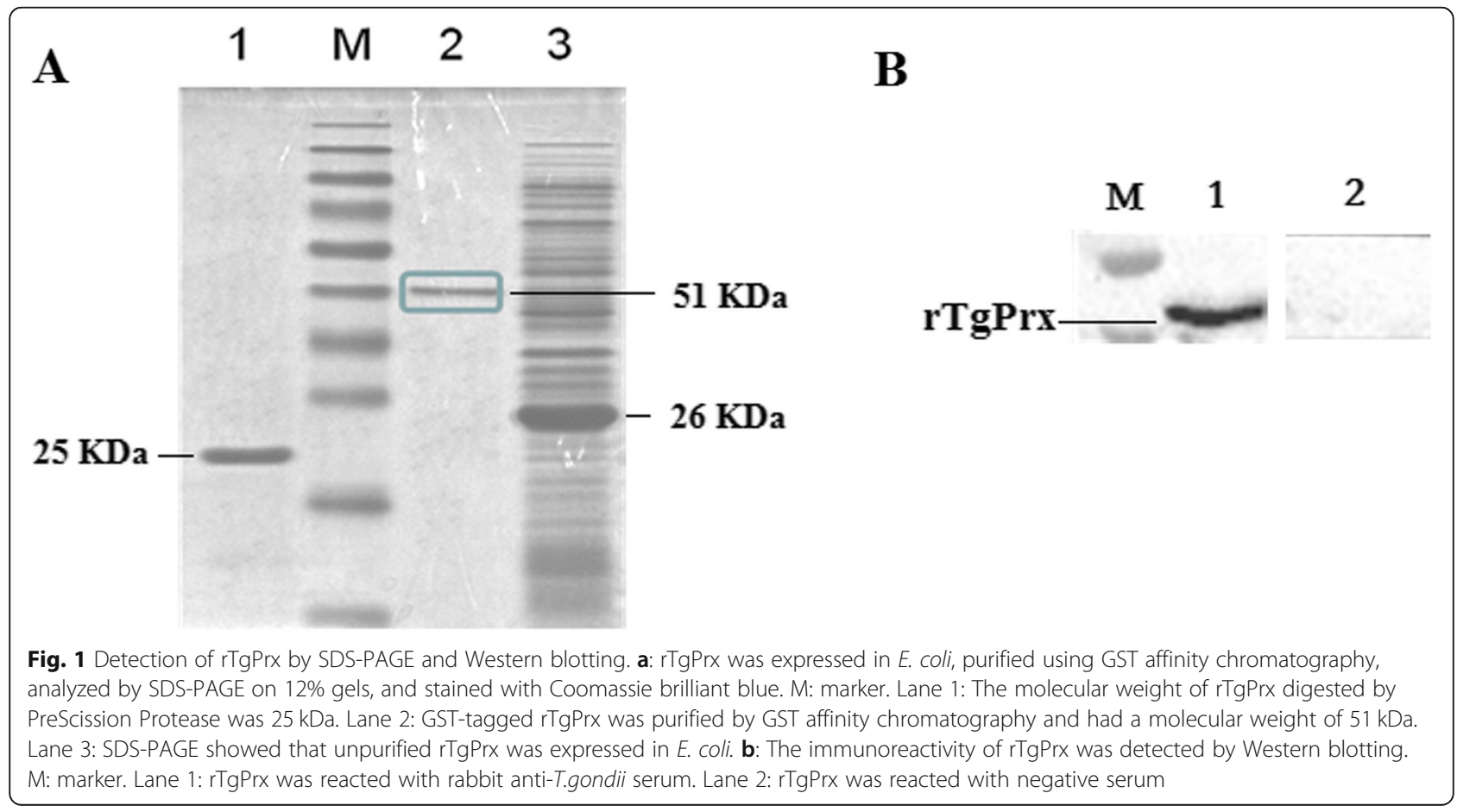




\section{Sensitivity analysis}

Positive serum samples from mice immunized with STAg were simultaneously analyzed by rTgPrx-DotIGSS, rTgPrx-ELISA, Western blotting (Additional files 1: Fig. S7), and a commercial ELISA kit for the antiToxoplasma IgG antibody. The positive T. gondii infection rates among the 40 serum samples were 97.5\% (39/ 40) for rTgPrx-Dot-IGSS, 95\% (38/40) for rTgPrxELISA, 90\% (36/40) for Western blotting, and 100\% (40/ 40) for the commercial ELISA kit (Table 1). The positive rates obtained with rTgPrx-Dot-IGSS, rTgPrx-ELISA and Western blotting did not differ significantly from those obtained with the commercial ELISA kit $(P=$ 1.000, $P=0.494$, and $P=0.116$, respectively), indicating that the sensitivity of rTgPrx-Dot-IGSS is comparable to that of the commercial ELISA kit.

\section{Specificity analysis}

Serum was collected from mice infected with PBS, $C$. sinensis, S. japonicum or $P$. berghei and analyzed by rTgPrx-Dot-IGSS, rTgPrx-ELISA, Western blotting and a commercial ELISA kit for the anti-Toxoplasma IgG antibody. The results of Dot-IGSS, ELISA and Western blotting using rTgPrx as the antigen showed that all serum samples were negative and lacked cross-reactivity. However, one serum sample from a mouse infected with $S$. japonicum was determined to be positive by the commercial ELISA kit. These results indicate that rTgPrxDot-IGSS has higher specificity than this commercial ELISA kit (Table 2).

\section{Repeatability analysis}

Forty serum samples positive for $T$. gondii and 20 serum samples negative for $T$. gondii from mice were analyzed in triplicate by rTgPrx-Dot-IGSS. The results of the repeated tests were consistent $(P<0.0001)$, showing that the rTgPrx-Dot-IGSS assay has good repeatability and stability.

\section{Detection of $T$. gondii infection in pregnancy serum by rTgPrx-dot-IGSS}

A total of 540 pregnancy serum samples were collected and analyzed with a commercial ELISA kit for the anti-Toxoplasma IgG antibody. Eighty-three of the serum samples were positive; thus, the T. gondii infection rate among the pregnant women was $15.4 \%$. The 83 serum samples confirmed to be positive with the commercial ELISA kit were analyzed by rTgPrxDot-IGSS, rTgPrx-ELISA and Western blotting. The positive rates were $95.18 \%(79 / 83)$ for rTgPrx-DotIGSS, $92.77 \%(77 / 83)$ for rTgPrx-ELISA, and $86.75 \%$ $(72 / 83)$ for Western blotting (Table 3$)$. The positive rate obtained with rTgPrx-Dot-IGSS did not differ significantly from that obtained with the commercial ELISA kit $(P=0.120)$, while those determined by rTgPrx-ELISA and Western blotting were appreciably lower $(P=0.028$ and $P=0.001$, respectively). These results indicate that rTgPrx-Dot-IGSS is comparable to the commercial ELISA kit for the diagnosis of T. gondii infection.

\section{Discussion}

As molecular biology techniques have been developed, recombinant antigens have recently been used instead of natural antigens, such as surface antigens (SAG1), dense granular antigens (GRA1 and GRA7) and rhoptry antigens (ROP18), for diagnostic tests [28-31]. Mass and standardized production of recombinant antigens is straightforward [9]. In this study, we constructed the recombinant plasmid pGEX-6P-1-TgPrx. pGEX-6P-1 is a highly efficient expression vector containing a GST tag, making recombinant protein purification easy and efficient [32]. pGEX-6P-1-TgPrx was transformed into E. coli BL21 for expression. We optimized the experimental conditions to maximize the expression levels of soluble proteins by using a low concentration of IPTG, reducing the induction temperature and extending the induction time. The results of preliminary experiments showed that the presence of the GST tag could affect the specificity of rTgPrx and cause nonspecific reactions during the detection of serum antibodies. Therefore, the GST tag was cleaved with PreScission Protease. PreScission Protease is a human rhinovirus type $3 \mathrm{C}$ protease containing a GST tag that enables fixation of proteins and removal of the GST tag [33]. The digestion time and volume of PreScission Protease used were adjusted according to the concentration of rTgPrx. The analysis of Imag J software confirmed that $95.6 \%$ purity of rTgPrx protein was obtained as the detection

Table 1 Sensitivity analysis of rTgPrx-Dot-IGSS

\begin{tabular}{llll}
\hline Test method & Number of samples ${ }^{\text {a }}$ & Number of positive samples & Positive rate \\
\hline rTgPrx-Dot-IGSS & 40 & 39 & 38 \\
rTgPrx-ELISA & 40 & $36.5 \%$ \\
Western blotting & 40 & $36.0 \%$ \\
Commercial ELISA kit & 40 & 40
\end{tabular}

Note: ${ }^{a}$ Serum from mice immunized with STAg. The serum titers were 1:800 and 1:1600, as determined by ELISA 
Table 2 Specificity analysis of rTgPrx-Dot-IGSS

\begin{tabular}{|c|c|c|c|c|c|c|c|c|c|}
\hline \multirow[t]{2}{*}{ Group } & \multirow{2}{*}{$\begin{array}{l}\text { Number of } \\
\text { samples }\end{array}$} & \multicolumn{2}{|c|}{ rTgPrx-Dot-IGSS } & \multicolumn{2}{|c|}{ rTgPrx-ELISA } & \multicolumn{2}{|c|}{ Western blotting } & \multicolumn{2}{|c|}{ Commercial ELISA kit } \\
\hline & & Positive & $\overline{\text { Negative }}$ & Positive & Negative & Positive & $\overline{\text { Negative }}$ & Positive & Negative \\
\hline PBS & 20 & 0 & 20 & 0 & 20 & 0 & 20 & 0 & 20 \\
\hline Clonorchis sinensis & 10 & 0 & 10 & 0 & 10 & 0 & 10 & 0 & 10 \\
\hline Schistosoma japonicum & 10 & 0 & 10 & 0 & 10 & 0 & 10 & 1 & 9 \\
\hline Plasmodium berghei & 10 & 0 & 10 & 0 & 10 & 0 & 10 & 0 & 10 \\
\hline
\end{tabular}

antigen. The immunoreactivity of purified rTgPrx was further verified by Western blotting.

In recent years, dot-based immunoassay technology (Dot-Blot, Dot-ELISA and dot immunogold filtration assay, et al) has attracted the attention of scholars [3436]. Initially, we used rTgPrx as the diagnostic antigen to establish a Dot-IGSS method for the detection of $T$. gondii infection in mice. The optimal dilution ratios of mouse serum and the colloidal gold-labeled secondary antibody, the optimal blocking solution, and the optimal blocking time for this method were explored. The optimal dilution ratios of mouse serum and goat anti-mouse IgG were determined to be 1 : 200 and 1:20, respectively. TBS containing 1\% BSA and $10 \%$ sheep serum was used as the blocking solution, and incubation was performed for $30 \mathrm{~min}$ at $37^{\circ} \mathrm{C}$. rTgPrx-Dot-IGSS was used to analyze 40 serum samples from mice immunized with STAg. The results indicated a positive rate of $97.5 \%$ and no crossreactivity. A previous study showed that the sensitivity and specificity of IgG ELISA with a single recombinant surface antigen (SAG1) or recombinant dense granular antigens (GRA1 and GRA7) in captive jaguars were 92.5 $\sim 97.5 \%$ and $83.3 \sim 91.6 \%$, respectively, and that the sensitivity and specificity were significantly increased when these antigens were mixed [30]. Therefore, the sensitivity of rTgPrx-Dot-IGSS could be increased by mixing rTgPrx with other specific antigens.

Furtherly, rTgPrx-Dot-IGSS was used to detect human Toxoplasmosis. Eighty-three positive serum samples were identified among 540 pregnancy serum samples by screening with a commercial ELISA kit for the antiToxoplasma IgG antibody. The 83 positive serum samples and 60 negative samples were reanalyzed by rTgPrx-Dot-IGSS, rTgPrx-ELISA and Western blotting. These results showed that rTgPrx-Dot-IGSS could be used to diagnose toxoplasmosis. However, 4 samples identified as positive by the commercial ELISA kit were identified as negative with rTgPrx-Dot-IGSS. This discrepancy has a few possible explanations. First, the antigen coating in the commercial ELISA kit was a mixed antigen with whole tachyzoite lysate, while $\operatorname{rTgPrx}$ is a single purified antigen with high specificity and slightly lower sensitivity than the antigen in the ELISA kit. Purification and mixing of highly specific antigens should be considered for future diagnosis. Second, the commercial ELISA kit might have produced false positive results due to antigen impurity, contamination of the detection reagents or experimental errors. Therefore, the specificity and sensitivity of commercial ELISA kits from different companies should be compared.

In addition, Only detection of IgG in serum was shown in the results. As we known, IgM appeared firstly during infection, but it didn't last long. In the preexperimental stage, we detected IgM from partly immunized mice. The results showed that rTgPrx-Dot-IGSS was feasible. However, IgM of the pregnancy serum hadn't been tested.

\section{Conclusions}

The rTgPrx could be described as valuable diagnostic antigens of toxoplasmosis. In this study, the rTgPrx-Dot-IGSS assay was established by detecting T.gondii infection in mice, and initially applied to the detection of human toxoplasmosis. It exhibited not only simple operation, a low cost and intuitive results but also moderate sensitivity, good specificity and strong repeatability. Thus, this method is a promising diagnostic tool for clinical diagnosis of toxoplasmosis.

Table 3 Detection of Toxoplasma in pregnancy serum samples

\begin{tabular}{|c|c|c|c|c|c|}
\hline \multirow[t]{2}{*}{ Test method } & \multicolumn{2}{|c|}{ Commercial ELISA kit } & \multicolumn{3}{|c|}{ Test result } \\
\hline & Positive & Negative & Positive & Negative & Positive rate \\
\hline rTgPrx-Dot-IGSS & 83 & 60 & 79 & 64 & $95.18 \%$ \\
\hline rTgPrx-ELISA & 83 & 60 & 77 & 66 & $92.77 \%$ \\
\hline Western blotting & 83 & 30 & 72 & 41 & $86.75 \%$ \\
\hline
\end{tabular}

Note: ${ }^{a}$ The positive rate is the number of positive cases determined with rTgPrx-Dot-IGSS, rTgPrx-ELISA or Western blotting divided by the number of positive cases determined with the commercial ELISA kit $\times 100 \%$ 


\section{Supplementary information}

Supplementary information accompanies this paper at https://doi.org/10. 1186/s12879-020-05414-8.

Additional file 1: Fig. S1. SDS-PAGE analysis of pGEX-6P-1/TgPrx/BL21 expression products induced by different concentrations of IPTG. Fig. S2. SDS-PAGE analysis of pGEX-6P-1/TgPrx/BL21 expression products at different induction times. Fig. S3. SDS-PAGE analysis of optimized expression temperature of pGEX-6P-1/TgPrx/BL21. Fig. S4. The optimization of the type of blocking solution and the blocking time for Dot-IGSS assay. Fig. S5. The antibodies dilution for Dot-IGSS assay determined by checkerboard titration. Fig. S6. Detection of T. gondii infection in mice by rTgPrx-Dot-IGSS. Fig. S7. Detection of T. gondii infection in mice by Western blotting.

\section{Abbreviations}

rTgPrx: Recombinant T. gondii peroxiredoxin protein; Dot-IGSS: Dotimmunogold-silver staining; ELISA: Enzyme-linked immunosorbent assay; IgG: Immunoglobulin G; T. gondii: Toxoplasma gondii

\section{Acknowledgments}

The authors would like to thank the study participants for their involvement in the study. We are grateful to the medical staff for collection of blood samples.

\section{Authors' contributions}

$\mathrm{ZL}$ and $\mathrm{XL}$ designed the study, performed experiments, and wrote the manuscript; LF prepared the mouse serum, collected the blood samples from pregnant women, and performed serological testing; FY analyzed the data; YL, RT and KZ designed the experiments; and KZ and YL contributed reagents and revised the initial manuscript draft. All authors read and approved the final manuscript.

\section{Funding}

This work was supported by grants from the Natural Science Fund of the Jiangsu Higher Education Institutions (No. 17KJB310017), the Natural Science Foundation of Jiangsu of China (No. BK20180994), the Fund for Postdoctoral Research in China (No. 2018 M632382), and the Training Programs of Innovation and Entrepreneurship for College Students in Jiangsu Province (No. 201910313062Y). The funders had no role in the study design, data collection and analysis, decision to publish, or manuscript preparation.

\section{Availability of data and materials}

The datasets included in the present study are available from the corresponding author on reasonable request.

\section{Ethics approval and consent to participate}

This study was approved by the Ethics Committee on Animal Research of Xuzhou Medical University (No. SCXK < SU > 2014-0003). The purpose of the study was explained to each participant. Written informed consent was provided by pregnant women.

\section{Consent for publication}

Not applicable.

\section{Competing interests}

The authors declare that they have no competing interests.

Received: 26 April 2020 Accepted: 11 September 2020

Published online: 22 September 2020

\section{References}

1. Kim K. The Epigenome, cell cycle, and development in Toxoplasma. Annu Rev Microbiol. 2018;72:479-99.

2. Barrett MP, Kyle DE, Sibley LD, Radke JB, Tarleton RL. Protozoan persister-like cells and drug treatment failure. Nat Rev Microbiol. 2019;17(10):607-20.

3. Rostami A, Riahi SM, Contopoulos-loannidis DG, Gamble HR, Fakhri Y, Shiadeh MN, et al. Acute Toxoplasma infection in pregnant women worldwide: a systematic review and meta-analysis. PLoS Negl Trop Dis. 2019;13(10):e7807
4. Torgerson PR, Mastroiacovo P. The global burden of congenital toxoplasmosis: a systematic review. Bull World Health Organ. 2013:91(7): 501-8.

5. Bigna JJ, Tochie JN, Tounouga DN, Bekolo AO, Ymele NS, Sime PS, et al. Global, regional and national estimates of Toxoplasma gondii seroprevalence in pregnant women: a protocol for a systematic review and modelling analysis. BMJ Open. 2019;9(10):e30472.

6. Deng H, Devleesschauwer B, Liu M, Li J, Wu Y, van der Giessen J, et al. Seroprevalence of Toxoplasma gondii in pregnant women and livestock in the mainland of China: a systematic review and hierarchical meta-analysis. Sci Rep. 2018;8(1):6218.

7. Jiang RL, Ma LH, Ma ZR, Hou G, Zhao Q, Wu X. Seroprevalence and associated risk factors of Toxoplasma gondii among Manchu pregnant women in northeastern China. Microb Pathog. 2018;123:398-401.

8. Dunay IR, Gajurel K, Dhakal R, Liesenfeld O, Montoya JG. Treatment of Toxoplasmosis: Historical Perspective, Animal Models, and Current Clinical Practice. Clin Microbiol Rev. 2018;31(4).

9. Rostami A, Karanis P, Fallahi S. Advances in serological, imaging techniques and molecular diagnosis of Toxoplasma gondii infection. Infection. 2018; 46(3):303-15.

10. Olariu TR, Blackburn BG, Press C, Talucod J, Remington JS, Montoya JG. Role of Toxoplasma lgA as Part of a Reference Panel for the Diagnosis of Acute Toxoplasmosis during Pregnancy. J Clin Microbiol. 2019;57(2).

11. Costa JG, Vilarino MJ. Antigens to detect the acute phase of toxoplasmosis in pregnant women: standardized comparison. Biomark Med. 2018;12(5):517-34.

12. Liu YS, Du WP, Chen M, Wu ZX. Comparative study of dot-immunogold silver staining and dot-ELISA for the detection of serum antibodies against Wuchereria bancrofti. Southeast Asian J Trop Med Public Health. 1994;25(4): $724-7$.

13. Liu YS, Du WP, Zheng KY, Fu LL, Chen M. Comparative study on rapid dotimmunogold staining and two immunogold silver staining assays for diagnosing Schistosomiasis japonica. Southeast Asian J Trop Med Public Health. 2005;36(1):79-82

14. Liu YS, Du WP, Wu ZX. Dot-immunogold-silver staining in the diagnosis of cysticercosis. Int J Parasitol. 1996;26(1):127-9.

15. Liu YS, Du WP, Xue JQ, Chen M, Ma QY, Zhang SH, et al. Combinations of three immunological assays for detecting anti-toxoplasma IgG in the sera of patients infected with Toxoplasma gondii. Southeast Asian J Trop Med Public Health. 1997;28(2):335-8.

16. Liu YS, Zheng KY, Chen M, Fu LL, Du WP, Shi ZX. Study on detecting antibodies to Toxoplasma gondii in pooled serum of blood donors by dotIGSS. Southeast Asian J Trop Med Public Health. 2001;32(3):558-61.

17. Ma GY, Zhang JZ, Yin GR, Zhang JH, Meng XL, Zhao F. Toxoplasma gondii: proteomic analysis of antigenicity of soluble tachyzoite antigen. Exp Parasitol. 2009:122(1):41-6.

18. Fereig RM, Kuroda Y, Terkawi MA, Mahmoud ME, Nishikawa Y. Immunization with Toxoplasma gondii peroxiredoxin 1 induces protective immunity against toxoplasmosis in mice. PLoS One. 2017;12(4):e176324

19. Li XY, Liu ZZ, Fu LL, Yan C, Du WP, Tang RX, et al. Cloning, over-expression and purification of the recombinant peroxiredoxin protein of Toxoplasma gondii. J Pathog Biol. 2012;7(4):276-9 290.

20. Nasiri M, Babaie J, Amiri S, Azimi E, Shamshiri S, Khalaj V, et al. SHuffle ${ }^{\text {TM }}$ T7 strain is capable of producing high amount of recombinant human fibroblast growth factor-1 (rhFGF-1) with proper physicochemical and biological properties. J Biotechnol. 2017;259:30-8.

21. Settles EW, Moser LA, Harris TH, Knoll LJ. Toxoplasma gondii upregulates interleukin-12 to prevent Plasmodium berghei-induced experimental cerebral malaria. Infect Immun. 2014;82(3):1343-53.

22. Da CA, Zorgi NE, Do NN, Galisteo AJ, de Andrade HJ. Gamma irradiation of Toxoplasma gondii protein extract improve immune response and protection in mice models. Biomed Pharmacother. 2018;106:599-604.

23. Yan C, Li B, Fan F, Du Y, Ma R, Cheng XD, et al. The roles of toll-like receptor 4 in the pathogenesis of pathogen-associated biliary fibrosis caused by Clonorchis sinensis. Sci Rep. 2017:7(1):3909.

24. Liu R, Ye F, Zhong QP, Wang SH, Chai T, Dong HF, et al. Comparative serum metabolomics between SCID mice and BALB/C mice with or without Schistosoma japonicum infection: clues to the abnormal growth and development of schistosome in SCID mice. Acta Trop. 2019:200:105186.

25. Al-Shaebi EM, Mohamed WF, Al-Quraishy S, Dkhil MA. Susceptibility of mice strains to oxidative stress and neurotransmitter activity induced by Plasmodium berghei. Saudi J Biol Sci. 2018;25(1):167-70. 
26. Chiao DJ, Shyu RH, Hu CS, Chiang HY, Tang SS. Colloidal gold-based immunochromatographic assay for detection of botulinum neurotoxin type B. J Chromatogr B Anal Technol Biomed Life Sci. 2004;809(1):37-41.

27. Liu Z, Yuan F, Yang Y, Yin L, Liu Y, Wang Y, et al. Partial protective immunity against toxoplasmosis in mice elicited by recombinant Toxoplasma gondii malate dehydrogenase. Vaccine. 2016;34(7):989-94.

28. Arab-Mazar Z, Fallahi S, Koochaki A, Haghighi A, Seyyed TS. Immunodiagnosis and molecular validation of Toxoplasma gondiirecombinant dense granular (GRA) 7 protein for the detection of toxoplasmosis in patients with cancer. Microbiol Res. 2016;183:53-9.

29. Ferra BT, Holec-Gasior L, Gatkowska J, Dziadek B, Dzitko K, Grazlewska W, et al. The first study on the usefulness of recombinant tetravalent chimeric proteins containing fragments of SAG2, GRA1, ROP1 and AMA1 antigens in the detection of specific anti-Toxoplasma gondii antibodies in mouse and human sera. PLoS One. 2019;14(6):e217866.

30. Reynoso-Palomar A, Moreno-Galvez D, Villa-Mancera A. Prevalence of Toxoplasma gondii parasite in captive Mexican jaguars determined by recombinant surface antigens (SAG1) and dense granular antigens (GRA and GRA7) in ELISA-based serodiagnosis. Exp Parasitol. 2020;208:107791.

31. Vargas-Montes M, Cardona N, Moncada DM, Molina DA, Zhang Y, GomezMarin JE. Enzyme-linked Aptamer assay (ELAA) for detection of Toxoplasma ROP18 protein in human serum. Front Cell Infect Microbiol. 2019:9:386.

32. Liu B, Liu GD, Guo HY, Zhu KC, Guo L, Liu BS, et al. Functiona characterization of NK-lysin in golden pompano Trachinotus ovatus (Linnaeus 1758). Dev Comp Immunol. 2020;107:103658.

33. Ame JC, Heberle E, Camuzeaux B, Dantzer F, Schreiber V. Purification of recombinant human PARG and activity assays. Methods Mol Biol. 1608;2017: 395-413.

34. Yazdani H, Sharafi SM, Yousefi H, Hadipur M, Sepahvand A, Darani HY Diagnosis of Giardia duodenalis infection using dot blot in comparison with microscopy. Infect Disord Drug Targets. 2016;16(3):178-81.

35. Chen X, Chen X, Lu X, Feng X, Wen H. The production and comparative evaluation of native and recombinant antigens for the fast serodiagnosis of cystic echinococcosis with dot immunogold filtration assay. Parasite Immunol. 2015:37(1):10-5.

36. Teimouri A, Modarressi MH, Shojaee S, Mohebali M, Rezaian M, Keshavarz H. Development, optimization, and validation of an in-house dot-ELISA rapid test based on SAG1 and GRA7 proteins for serological detection of Toxoplasma gondii infections. Infect Drug Resist. 2019;12:2657-69.

\section{Publisher's Note}

Springer Nature remains neutral with regard to jurisdictional claims in published maps and institutional affiliations.

Ready to submit your research? Choose BMC and benefit from:

- fast, convenient online submission

- thorough peer review by experienced researchers in your field

- rapid publication on acceptance

- support for research data, including large and complex data types

- gold Open Access which fosters wider collaboration and increased citations

- maximum visibility for your research: over $100 \mathrm{M}$ website views per year

At $\mathrm{BMC}$, research is always in progress.

Learn more biomedcentral.com/submissions 